\title{
Factors contributing to the Success of Aquaculture Field Schools
}

\author{
G S. Saha ${ }^{1}$, H K. De ${ }^{1}$, A S. Mahapatra ${ }^{1}$ and N. Panda ${ }^{1}$
}

\begin{abstract}
ICAR- Central Institute of Freshwater Aquaculture (CIFA) had piloted four Aquaculture Field Schools (AFS), a model of farmer to farmer extension, in Odisha and Chhattisgarh states in India. The AFS' are attracting farmers and stakeholders as they provide a platform to share experience and enable cross learning. In this research, an attempt has been made to identify the factors that contribute to the successful performance of AFS. Data were collected from 166 user farmers, selected randomly from the list available with operators. Five variables viz., age of fish farmer, frequency of visit to AFS, duration of visit, interaction with the fellow farmers and advocation of advanced technologies of ICAR-CIFA to other farmers were observed to be significantly contributing to yield of fish. The Multiple correlation coefficient, $R=0.48$, indicated that there is a significant and positive correlation between the observed and predicted value of fish yield.
\end{abstract}

Keywords: Aquaculture Field Schools; Factors; Farmer; Extension; Odisha; Chhattisgarh

\section{INTRODUCTION}

Aquaculture extension services have been focussing primarily on transferring aquaculture technologies, improving fish farming skills and promoting good practices in technical areas, such as site selection, farming systems and technology, seed production, feed management, fish disease and biosecurity, water management, harvesting, post-harvest handling, marketing and record keeping (FAO, 2017). Effective extension service has contributed to increased aquaculture production and has the potential to contribute to economic development of rural fish farmers (Tu and Giang, 2002).
Extension has undergone profound changes over time with an increasing scope in terms of both contents and recipients (FAO, 2017). While agricultural (including aquaculture) extension often is narrowly defined as "technology transfer", it should be broadened to encompass human resource development that focuses on learning and building farmers' self-confidence and their capacities in networking, problem solving and decision making. Aquaculture extension services should be provided to not only fish producers but also to ancillary and supporting businesses, such as seed producers, feed formulators, net makers,

${ }^{1}$ ICAR- Central Institute of Freshwater Aquaculture, Kausalyaganga, Bhubaneswar, Odisha 752104

Received : 06-03-2020; Accepted : 05-06-2020 
harvesting teams, fish traders and other key players in the value chain (FAO, 2017).

Aquaculture Field School (AFS) is a school without walls for improving decision making capacity of farming community in aquaculture. It is a participatory extension approach whereby fish farmers are given opportunity to make choice in the methods of aquaculture production through discovery based approach (De et al. 2012 \& 2013). AFS is composed of a group of farmers who regularly meet and share information among themselves. Typical group strength is 2025. The basic tenets of AFS are: fish farmers are experts; the fish farm is a learning place; fishery extension worker as facilitator not teacher; scientists/SMS (subject matter specialist) work with rather than lecture them; learning materials are learner centered. The principles of farmer field school can be easily incorporated in the aquaculture venture where the entrepreneurs/farmers after being trained by research institute, can train other small farmers in that area about the scientific practices of the fish farming. The major objectives of the Aquaculture Field School (AFS) are to build farmers' capacity to analyze their production systems, identify problems, test possible solutions and eventually adopt the practices most suitable to their farming system. The principle of AFS is similar to that of Farmers Field School (FFS) implemented in agriculture. A Farmer Field School (FFS) is a forum where farmers and trainers carry out collective and collaborative inquiry, debate observations, apply their previous experiences and present new information from outside the community with the purpose of initiating community action in solving community problems (Minjauw, 2002).

The ICAR-Central Institute of Freshwater Aquaculture, Bhubaneswar has established four aquaculture field schools (AFS), three in Odisha and one in the state of Chhattisgarh, to promote farmer to farmer extension. The AFSs organizes training programmes for farmers with sponsorship from Agriculture Technology Management Agency (ATMA), Odisha Skill Development Authority and other development agencies. Field school aims to increase the capacity of groups of farmers to test new technologies in their own fields and to assess the relevance of results to their particular circumstances (Braun et al. 2000). There is a need to integrate the curriculum of different steps in scientific method of aquaculture like where to rear, when to rear, how to rear, how to harvest, how to market the product etc. These field schools cover a wide area where the progressive farmers are there and through them the technology of fish culture like culture and seed production of carp, catfish, and air breathing fish, ornamental fish etc. are disseminated.

Key strengths of the FFS approach can be broadly categorized as: the enhancement of human and social capital and a key entry point for new practices and technologies (Watson, 2008). Within a short span of their establishment all the AFSs have proved to be the ground for new, meaningful and participatory learning about the scientific practices in aquaculture. Farmers' practical problems are regularly being analyzed, their 
Factors contributing to the Success of Aquaculture Field Schools

capacity enhanced and quality decision marking ability strengthened through these field schools.

Since the AFSs are piloted by the Institute, it is imperative to know whether the AFSs are promoting parallel extension or not. It is also important to identify the factors that determine success of AFS as a model of farmer to farmer extension. The study was conducted with these two specific objectives. An insight into the functioning of AFS and the factors that influences its success would be of immense significance for upscaling and replication of this model.

\section{METHODOLOGY}

Successful performance of AFS would result in improved information access to participating farmers. Information exchange and skill upgradation that takes place in AFS also contribute to enhancing yield as well as income of farmers. In this study success has been measured in terms of yield levels of farmers, which is a measurable and quantifiable variable. Direct indicators and physicochemical parameters e.g., seed, feed, fertilizer, health management etc. do influence yield. However, the purpose of this study was to understand AFS as a novel approach of extension and how this novel approach of extension is contributing to enhancing yield. From the perspectives of extension advisory to farmers who visit AFS to learn technology and share information about aquaculture, the variables were studied viz. age and qualification of fish farmer, primary occupation, frequency of visit to AFS, occupation, family size, duration of visit, interaction with the fellow farmers, advocation of advanced technologies of ICARCIFA to other farmers which are independent variables.

Data were collected from a total of 166 farmers from four AFSs viz. AFS Sarakana (80), AFS Bhatpadagarh (35), AFS Durg (24) and AFS Baisinga (27) using semi-structured interview schedule. Respondents were selected randomly from the list of farmers being maintained at the AFS by its operator. The schedule was prepared after consulting experts in the field of aquaculture extension. Data were collected by personally interviewing the farmers, who visit AFS on a regular basis. The survey was conducted during 2016-18. Data include age, qualification, primary occupation, family size of the farmers, duration of visit to AFS, frequency of visit, water area and fish yield of visiting farmers, type of fish farming, scope for interaction with experienced farmers, recommendation for new technology/ practice by the fish farmers.

\section{Analysis}

By using SPSS, Multiple regression analysis was performed with yield as dependent variable and eight independent variables i.e. age of farmer, qualification of farmer, primary occupation, and frequency of visit to AFS, duration of visit, interaction with the fellow farmers, confidence of the facilitator of the AFS, recommendation of new technology/practice to other farmers. Coefficient of determination $\left(R^{2}\right)$ has also been worked out to quantify to what extent yield is explained by the selected independent variables. 


\section{FINDINGS AND DISCUSSION}

Primary information about the respondents

Majority (63\%) of the respondents are visiting AFS since last 4-6 years. In case of Baisinga farmers reported to have visited it even before the same was rechristened as AFS. It was learnt during interview that farmers used to visit it for buying fish seeds, other inputs and also for consultation with the facilitator. The majority of the respondents (35\%) visit AFS on quarterly basis followed by once a year (25\%) and once in six months (20\%). Farmers who visit annually do so for buying seeds as they practice 'grow out' culture. It was informed by the farmers that they visit AFSs for sharing information with their fellow farmers. Majority of the respondents were small farmers possessing water bodies of less than one acre. Around 19\% of them were having pond area of more than 3 acres. AFS is run by the operator who is trained and mentored by the institute. As the operator himself practices recommended package, it is expected that he would disseminate the same to other farmers. The data indicate that as many as $86 \%$ of the respondents agreed to have discussed at AFS the pros and cons of new practice/recommendation of the institute. Others visiting AFS benefit from the operator farmer's experience and receive his or her guidance. Eighty five percent of the respondents have indicated that they were able to gain knowledge from the interaction with the fellow farmers at AFS. Yield levels reported by $86 \%$ of respondents were in the range of $1000-1500 \mathrm{~kg} / \mathrm{acre}$.

Fish yield is governed by several factors that includes biological, physical,

Table 1.

Regression Analysis

\begin{tabular}{|l|l|c|c|c|c|c|c|c|c|}
\hline \multicolumn{2}{|c|}{ Model } & \multicolumn{2}{|c|}{$\begin{array}{c}\text { Unstandardized } \\
\text { Coefficients }\end{array}$} & $\begin{array}{c}\text { Standardized } \\
\text { Coefficients }\end{array}$ & $\mathrm{t}$ & \multicolumn{2}{c|}{ Sig. } & \multicolumn{3}{c|}{ Correlations } \\
\hline & B & $\begin{array}{c}\text { Std. } \\
\text { Error }\end{array}$ & Beta & & & $\begin{array}{c}\text { Zero- } \\
\text { order }\end{array}$ & Partial & Part \\
\hline 1 & (Constant) & 632.433 & 146.397 & & 4.320 & .000 & & & \\
\hline & AGE & 5.328 & 2.304 & .172 & 2.313 & .022 & .282 & .182 & .162 \\
\hline & QUALF & -14.402 & 19.992 & -.051 & -.720 & .472 & -.029 & -.057 & -.050 \\
\hline & POCCP & 73.826 & 46.239 & .113 & 1.597 & .112 & .121 & .126 & .112 \\
\hline & FRQVIS & 9.148 & 4.206 & .159 & 2.175 & .031 & .258 & .171 & .152 \\
\hline & DURATION & 26.761 & 11.477 & .172 & 2.332 & .021 & .238 & .183 & .163 \\
\hline & INTERACT & 125.923 & 62.927 & .156 & 2.001 & .047 & .299 & .158 & .140 \\
\hline & CONFIDNCE & 14.110 & 83.437 & .012 & .169 & .866 & .109 & .013 & .012 \\
\hline & RECCOM & 136.470 & 64.688 & .163 & 2.110 & .036 & .244 & .166 & .147 \\
\hline
\end{tabular}


infrastructural, technological and farmer's socio-economic conditions. Extension service too influences farmers yield substantially. In this research a parallel extension i.e., farmer to farmer extension approach was piloted. Hence extension and advisory service related variables were identified and their relation with yield was worked out. In order to identify the variables contributing to the success of AFS, Multiple regression analysis was carried out with eight independent variables i.e. age (age), qualification (qualf), primary occupation (росcp), frequency of visit (frqvis), duration of visit (duration), interaction with the fellow farmers (interact), confidence of the facilitator of the AFS (confidence), recommendation of new technology/practice to other farmers (reccom). Since fish yield of the farmers is operationalized as an indicator of success of the AFS, the multiple regression analysis was performed by taking fish yield as the dependent variable.

\section{Dependent Variable: YIELD}

From Multiple linear regression analysis (Table 1), it is revealed that out of 8 independent variables, only 5 variables viz., age of fish farmers (age), frequency of visit by the farmer to the AFS (fravis), duration of visit to the AFS since establishment (duration), interaction with the fellow farmers (interact), advocation of advanced technologies of ICARCIFA to other farmers (reccom) are significantly contributing to the yield of fish (Kg/acre), yield.

The model summary (Table 2 ) shows that the coefficient of determination, $R^{2}=$ 0.233 which implies that $23 \%$ of total variability in yield ( $\mathrm{Kg} / \mathrm{acre})$, the dependent variable is explained by 5 independent and significant variables namely age, frequency of visit, duration, interaction and recommendation.

The Multiple correlation coefficient, $\mathrm{R}=0.48$ indicates that there is a significant and positive correlation between the observed and predicted value of fish yield ( $\mathrm{Kg} / \mathrm{acre})$.

The linear regression equation is best fitted as :

$\hat{Y}=632.433+0.022$ age +0.031 fravis + 0.021 duration +0.04 interact +0.036 reccom

where $\hat{Y}$ is the predicted value of fish yield.

The FFS approach represents a paradigm shift in agricultural extension and can

Table 2.

\section{Model Summary}

\begin{tabular}{|l|l|l|l|l|l|l|l|l|l|}
\hline Model & R & R Square & $\begin{array}{l}\text { Adjusted } \\
\text { R Square }\end{array}$ & $\begin{array}{l}\text { Std. Error } \\
\text { of the } \\
\text { Estimate }\end{array}$ & \multicolumn{4}{|c|}{ Change Statistics } \\
\hline & & & & & $\begin{array}{l}\text { R Square } \\
\text { Change }\end{array}$ & F Change & df1 & df2 & $\begin{array}{l}\text { Sig. } \\
\text { Change }\end{array}$ \\
\hline 1 & $.483(\mathrm{a})$ & .233 & .194 & 260.581 & .233 & 5.976 & 8 & 157 & .000 \\
\hline
\end{tabular}

Predictors: (Constant), RECCOM, AGE, QUALF, POCCP, CONFIDNCE, FRQVIS, DURATION, INTERAC 
be viewed as a capacity-building investment in the sector of education, information, and training. Farmers provide extension services to fellow farmers by sharing technical knowhow and experiences or helping them solve problems. The effectiveness of farmer-tofarmer extension is vital to the validity of the trickle-down modality observes FAO (2017). Farmer-to-farmer extension is a vital aspect of participatory extension methods such as Aquaculture Field School. The participating fish farmers in an FFS develop their skills during the FFS activities at the communal experimental field/pond, and then adopt these practices and techniques on their individual fields/ponds and disseminate the corresponding knowledge to friends, relatives and neighbors.

\section{CONCLUSION}

AFS is becoming a one stop solution for fish farmers. Frequency of visit, quality of interaction, length of association with AFS lends credence to the fact. The opportunity for discussion on recommended practices before adoption facilitate informed decision making by the farmers. The study concludes that improved extension and advisory service made available through AFS has contributed as much as $23 \%$ of the yield. This once again underscores the role of aquaculture extension in bridging the yield gap. AFS approach relied heavily on non-monetary inputs with technical advice and interaction as primary intervention. Sharing of experiences with the lead farmer at the AFS has brought in confidence among them in scientific fish farming. This approach of 'farmer to farmer' extension with no physical input would certainly be sustainable in the long run.

\section{REFERENCES}

Braun, A.R, Thiele G \& Fernández, M. (2000). Farmer Field Schools and Local Agricultural Research Committees: Complementary Platforms for Integrated Decision-Making in Sustainable Agriculture, AgREN Network Paper No. 105, London, UK: AgREN/ODI, pp. 16

De, H. K, Saha, G. S \& Radheyshyam (2012). Training and sensitizing the farmers in fish farming through Aquaculture field School. Indian Farming, 62(2): 31-33.

De, H. K, Saha, G. S \& Radheyshyam (2013). Aquaculture field schools to promote farmer to farmer extension. Journal of Global Communication 6(2): 77-85.

FAO. (2017). Sub-committee on Aquaculture - Extension for aquaculture development. Ninth Session Rome 24-27 Oct. 2017. COFI:AQ/IX/2017/7.

Minjauw, B., Muriuki, H.G., \& Romney, D. (2002). Development of the Farmer Field School Methodology for Smallholder Dairy Farmers in Kenya. Paper presented at International Learning Workshop on Farmer Field Schools (FFS): Emerging Issues and Challenges, 21-25 October 2002, Yogyakarta, Indonesia.

Tu, N.V \& Giang, T.T. (2002). Improving the Efficiency of Aquaculture Extension Activity in the Southeastern Provinces of Southern Vietnam. In: Edwards, P., Demaine, $\mathrm{H}$. and Little, D.C. (Eds), Rural Aquaculture. 
Factors contributing to the Success of Aquaculture Field Schools

Wallingford, UK: CABI Publication, pp. 285-300.

Watson, D.J. (2008). Community Farmer Field School Animal Health Facilitators:
Hybridizing Private Animal Healthcare and Capacity Building in Remote Pastoralist Areas, Research Report 14, ILRI, Nairobi. 